\title{
Climate changes and post-nuptial migration strategy by two reedbed passerines
}

\author{
Guillaume Péron ${ }^{1,2}$, Pierre-Yves Henry ${ }^{1,3}$, Pascal Provost ${ }^{4}$, Olivier Dehorter ${ }^{1}$, \\ Romain Julliard ${ }^{1, *}$ \\ ${ }^{1}$ UMR 5173 MNHN-CNRS-UPMC, Centre de Recherche sur la Biologie des Populations d'Oiseaux, CP51, 55 rue Buffon, \\ 75005 Paris, France \\ ${ }^{2}$ UMR 5175, Centre d'Ecologie Fonctionnelle et Evolutive, Centre National de la Recherche Scientifique, 1919 route de Mende, \\ 34293 Montpellier Cedex 5, France \\ ${ }^{3}$ UMR 7179 MNHN-CNRS, Département Ecologie et Gestion de la Biodiversité, Muséum National d'Histoire Naturelle, \\ 1 avenue du Petit Château, 91800 Brunoy, France \\ ${ }^{4}$ Maison de l'Estuaire, Observatoire Avifaune de la ZPS Estuaire et Marais de la Basse Seine, \\ Réserve Naturelle Nationale de l'Estuaire de la Seine, 20 rue Jean Caurret, 76600 Le Havre, France
}

\begin{abstract}
Phenology of biological systems is the expression of selective pressures forcing organisms to match their energy requirements to seasonal variations in resource availability. For longdistance migrant organisms, migration strategy is shaped by the availability and quality of stopovers during a precise time period. Ongoing climate changes alter the usual spatial and temporal distribution of resources, and, as a result, migrant species return earlier to their breeding grounds. Less is known on the evolution and determinants of timing of departure to wintering grounds, i.e. postbreeding migration. We analysed timing of post-nuptial migration and stopover strategy with capture-mark-recapture (CMR) data in 2 reedbed insectivorous passerines: the sedge warbler Acrocephalus schoenobaenus, specialised on a thermo-dependant prey, and the generalist reed warbler A. scirpaceus. Spring temperatures increased through years $\left(0.16 \pm 0.047^{\circ} \mathrm{C} \mathrm{yr}^{-1}\right)$, and studied species migrated earlier in recent years $\left(-0.73 \pm 0.086 \mathrm{~d} \mathrm{yr}^{-1}\right)$. Autumnal migration phenology was negatively related to spring (March) temperature $\left(-2.54 \pm 0.19 \mathrm{~d}^{\circ} \mathrm{C}^{-1}\right)$, whereas it was not related to autumnal temperatures. We suggest that this results from a major time shift (i.e. advance) in biomass production caused by global warming. Stopover duration (estimated by CMR analysis) was positively related to body mass gain, with a trend for a stronger effect in the specialised species. However, neither stopover duration nor body mass gain were related to spring temperature, suggesting that the advance in migration timing efficiently adapted bird phenology to temporal variations in resources.
\end{abstract}

KEY WORDS: Climate change - Stopover duration - Optimal migration - Acrocephalus scirpaceus · Acrocephalus schoenobaenus · Capture-Mark-Recapture

\section{INTRODUCTION}

Over the past 2 decades spring temperature has increased in the Northern Hemisphere temperate regions (Trenberth et al. 2007). These ongoing global climate changes have disturbed usual phenological patterns of distribution and abundance of resources. Phenology of biological systems is the expression of selective pressures forcing organisms to match their energy requirements to seasonal variations in resource availability. There is already compelling evidence that plants and animals are affected by climate changes, particularly by modifying their phenological patterns (e.g. Myneni et al. 1997, Roy \& Sparks 2000, Root et al. 2003, Cleland et al. 2006, Grosbois et al. 2006, Rivalan et al. 2007). For example, many bird species lay eggs earlier in spring to adapt to changes in prey phenologies (Crick et al. 1997, Crick \& Sparks 1999, Both \& 
Visser 2001, Both et al. 2005). As migration dates are most likely plastically adjusted to experienced environmental conditions, rapid adjustments of migration phenology to changing environmental conditions are expected. Rapid changes of migration timing were quantified from spring phenology of long-distance migrants (Lehikoinen et al. 2004, Jonzén et al. 2006, Rubolini et al. 2007, this issue, and references therein). Furthermore, since migration date also has a genetic basis (Møller 2001), climate change could induce a heritable, evolutionary response of migration timing.

There is less information available on the impact of climate change on the timing and ecology of autumnal, post-nuptial migration (Gatter 1992, Sokolov et al. 1999, Sparks \& Braslavska 2001, Cotton 2003, Jenni \& Kéry 2003, Lehikoinen et al. 2004, Gordo \& Sanz 2006, Sokolov 2006). Every possible pattern of change of post-breeding migration timing (no change, later departure date, earlier departure date) has been reported (e.g. Lehikoinen et al. 2004). Inter-annual variation in post-breeding behaviour seems to depend on ecology and life-history traits of bird species. For instance, short-distance migrants and species with variable reproductive effort left later in recent warmer years (Jenni \& Kéry 2003), suggesting that these species possibly benefit from climate warming through increased reproductive effort. Some species adjust the choice of their wintering ground to new temperature conditions (Austin \& Rehfisch 2005, Rivalan et al. 2007), or increase the time spent on their breeding grounds (Gordo \& Sanz 2006). On the opposite hand, among long-distance migrants, the date of departure from breeding grounds decreased throughout the 20th century, but this relationship is controversial: although several studies report earlier departure of some longdistance migrants in recent warmer years, most found that migrants did not change or even delayed their departure date (review in Lehikoinen et al. 2004, Sokolov 2006). Response of migrant birds to warmer, longer autumn is hence contrasted. Few studies analysed the effect of temperature, and, among those that did, most attempted to correlate autumnal migration timing to temperatures in autumn or during the breeding season (e.g. Gordo \& Sanz 2006). However, spring temperatures are likely a better determinant of autumnal migration timing than summer or autumnal temperatures (Sokolov et al. 1999, Sokolov 2006) under 2 main hypotheses that we will develop in the present study: (1) fitness benefits from early arrival at wintering grounds and (2) a temporal constraint results from the phenology of food availability at stopover sites.

The first objective of this study was to test for an advance in post-breeding migration date and, if found, to determine which temperatures from spring or autumn were the best predictors. The second objective was to test the 2 hypotheses that explain why birds do not take advantage of climate change to spend more time on the breeding grounds and eventually lay more clutches. The third objective was to address which patterns of phenotypic plasticity and/or natural selection are most likely to explain the observed temporal changes in migration phenology, under the assumption that if plasticity is mainly involved, the observed changes in stopover ecology should be better explained by a physical explanatory variable, such as temperature, than by a linear year effect (Jonzén et al. 2006).

These predictions were explored by correlative analysis of the effects of monthly mean temperatures on post-breeding migration timing in 2 trans-Saharan migrant birds: the sedge warbler Acrocephalus schoenobaenus (SW) and the reed warbler A. scirpaceus (RW). SW diet during post-breeding migration is mainly composed of reed aphids Hyalopterus pruni (Bibby \& Green 1981), whereas RW is a generalist insectivore (Bibby \& Green 1981, Idrissi et al. 2004). These inter-specific diet differences are used hereafter to discriminate the 2 hypotheses about which mechanisms select for advanced migration in response to warmer years. We acknowledge that no causal relationship between diet and behaviour can be formally tested in the present study. Experimental manipulations of food availability and/or comparative analysis involving more species would be required to validate the interpretations of correlative results proposed hereafter.

In the first hypothesis, early arrival at wintering grounds increases fitness, possibly through acquisition of a better wintering territory (Marra et al. 1998, Salewski et al. 2002, Studds \& Marra 2007, this issue). As long-distance migrants arrive earlier at their breeding grounds, and breed earlier, in warmer springs (likely for RW, Bergmann 1999, Crick \& Sparks 1999, Schaefer et al. 2005, and, for SW, Crick \& Sparks 1999; demonstrated for numerous other Palearctic insectivorous passerine migrants: Jonzén et al. 2006), migrants should also depart earlier in autumn, once breeding is achieved, in order to reach their wintering grounds as soon as possible. In this hypothesis, timing of autumnal migration should be at least partly, if not mainly, determined by spring temperatures, and both studied species should migrate earlier in autumns following warm springs. This is analogue to a complete time shift in the annual life cycle of long-distance migrants (Cotton 2003, and see Fig. 2 in Gordo 2007, this issue).

In the second hypothesis, timing of autumn migration is determined by availability of food resources en route. In this hypothesis, the birds are constrained to track the changes in the phenology of their insect prey. Following Bibby \& Green (1981), we suppose that 
warmer springs induce earlier appearance of the aphid abundance peak in autumn, because all primary production (Cleland et al. 2006) and hence secondary production is advanced by warmer springs. The constraint is then stronger for SW (the aphid specialist) because aphid populations are characterised by a short period of availability. Hence, under this hypothesis, SW should depart breeding grounds earlier in warmer years to track resource availability at stopover sites, and onset of its migration should be correlated to spring temperatures. Because of its generalist diet, RW should be less affected by among-year variations in stopover condition, and its migration timing should not correlate to spring temperatures. In terms of predictions, the second hypothesis predicts that spring temperature will correlate to migration timing in SW only, or at least more strongly in SW, whereas the first hypothesis predicts no interaction between species and temperature. In both hypotheses, we furthermore compared the effects of temperature and year to determine the extent to which plasticity is involved (Jonzén et al. 2006), and evaluated the extent to which a warm autumn can release the constraint by comparing models in which spring and autumn temperatures interact.

To further investigate response of these 2 migrants to a changing stopover environment, we estimated 2 other variables of the stopover ecology: stopover duration (SOD) and daily mass gain (DMG). These 2 variables are linked in the frame of optimal migration theory (OMT; Alerstam \& Lindström 1990). Intuitively, the higher the food availability, the quicker birds fatten, and the quicker they leave the stopover site. However, OMT predicts the opposite pattern: individuals should continue to store fat as long as the DMG at the site is higher than the average expected DMG at forthcoming sites, further south in the case of postbreeding migration of RW and SW (Bibby \& Green 1981, Alerstam \& Lindström 1990, Hedenström et al. 2007, this issue). This strategy should be stronger in SW: if the populations of aphids peak during a specific time frame that is linked with spring temperature, SW that encounter high food availability should not move further south, where the resource is likely to already be scarce; whereas, for RW, the constraint is weaker because they rely on a broader spectrum of food resources likely to be more uniformly distributed along their migration route (Bibby \& Green 1981, Schaub \& Jenni 2001, Idrissi et al. 2004). The prediction is then that variation in site quality (as experienced by the birds at the time they stop at the site), quantified by a proxy (daily DMG), will correlate more strongly to stopover duration for SW than for RW. This prediction is likely to be impacted by climate change if migrants do not efficiently track the changes in their en route food resource phenology: if migrants arrive at stopover sites after the abundance peak of their prey, we predict a decrease in DMG and in SOD, particularly for SW (the aphid specialist); however, if the advance in migration timing is sufficient, there should be no such decrease because the experienced food availability does not change.

\section{METHODS}

\subsection{Study species}

Acrocephalus schoenobaenus (SW) and A. scirpaceus (RW) are small (10 to $14 \mathrm{~g}$ in the breeding season), insectivorous passerines breeding in wetlands of the Palearctic. The populations concerned in the present study breed in north-western Europe. They migrate through coastal western France from late July to late September and stopover essentially in reedbeds. Their winter quarters are located in sub-Saharan Africa, where they occupy grasslands and wetlands (Cramp 1992).

\subsection{Data collection}

Reedbed passerines post-nuptial migration was monitored by capture-mark-recapture (CMR), using mist-nets, at 3 sites that represent the most important reedbeds in coastal western France: Marais du Hode (Site S76: Seine river estuary, $49^{\circ} 27^{\prime} \mathrm{N}, 0^{\circ} 26^{\prime} \mathrm{E}_{\text {; }}$ 19912 SW and 31864 RW between 1983 and 2005; stopover analysis was performed from 1994 onward because recaptures were too few in earlier years), Etang de Trunvel (Site S29: Audierne's Bay, $47^{\circ} 55^{\prime} \mathrm{N}, 04^{\circ} 19^{\prime} \mathrm{W}$; 33271 SW and 13416 RW between 1994 and 2005; Bargain et al. 2002) and Île du Massereau (Site S44: Loire river estuary, $47^{\circ} 14^{\prime} \mathrm{N}, 01^{\circ} 55^{\prime} \mathrm{W} ; 37208 \mathrm{SW}$ and 21409 RW between 1994 and 2006; Caillat et al. 2005).

At $\mathrm{S} 76$, capture sessions lasted $16 \mathrm{~d}$ on average $(\mathrm{SD}=$ 7.0) in the period from 1 August to 5 September. Capture dates (i.e. dates at which nets were opened) advanced with years $\left(-0.58 \pm 0.077\right.$ [SE] $\mathrm{d} \mathrm{yr}^{-1}, \mathrm{r}^{2}=$ $0.74, \mathrm{p}<0.01)$, with the mean capture date on 22 August ( $\mathrm{SD}=4.0$ ). At $\mathrm{S} 44$, capture sessions lasted $46 \mathrm{~d}$ on average $(\mathrm{SD}=15)$ between 15 July and 15 Septenber. Capture sessions were earlier in recent years $\left(-1.13 \pm 0.30[\mathrm{SE}] \mathrm{d} \mathrm{yr}^{-1}, \mathrm{r}^{2}=0.55, \mathrm{p}<0.01\right)$, with the mean capture date on 18 August ( $\mathrm{SD}=5.9$ ). At S29, capture sessions lasted $50 \mathrm{~d}$ on average (SD $=9.6$ ) between 15 July and 15 September. Capture session dates were similar through years $(p>0.5)$, with the mean capture date on 16 August $(\mathrm{SD}=2.1)$. The catching effort per day, i.e. number of mist-nets and duration of CMR sessions in days, varied within and among years. The dependent variable used to quantify the 
migration flux per species was therefore a capture index, noted $N_{\mathrm{p}}$ and computed as the number of individuals captured per meter of net per day.

Temperature data were obtained from the Meteo France stations of Cap de la Hève $\left(49^{\circ} 30^{\prime} 36^{\prime \prime} \mathrm{N}\right.$,

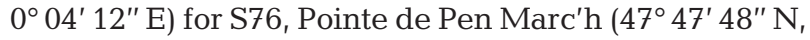
$\left.4^{\circ} 22^{\prime} 24^{\prime \prime} \mathrm{W}\right)$ for S29, and Saint-Nazaire Montoir $\left(47^{\circ} 19^{\prime} 00^{\prime \prime} \mathrm{N}, 2^{\circ} 10^{\prime} 00^{\prime \prime} \mathrm{W}\right)$ for S44. Monthly means (computed from daily means) are hereafter referred to as $T_{i}$ standing for temperature in the $i$ th month. Temporal trends on monthly mean temperatures were tested with linear regressions.

\subsection{Data analysis}

\subsubsection{Migration phenology, peak dates and correlations with temperature}

Timing of migration was characterised each year for Site $\mathrm{S} 76$ by the migration peak dates, i.e. the estimated dates at which $N_{\mathrm{p}}$ was maximum. The trapped birds were most likely heterogeneous in origin, age and quality; hence multimodality in the abundance pattern could be expected. However, visual examination of the data reveals that 1 mode of $N_{\mathrm{p}}$ dominated. A modelling method assuming unimodality thus seemed reasonable to extract the main information on timing of migration. The variation in session durations and dates made necessary the use of a method able to estimate peak date even if the peak occurred outside of one given capture session. For this purpose, 3 alternative nonlinear models were fitted to daily $N_{\mathrm{p}}$ data, with the least-squares method. We have used the following parametric functions (where $t$ is the time in days and $a$, $b$ and $c$ are the parameters to be estimated):

$$
\begin{aligned}
& f(x)=a x^{2} \mathrm{e}^{-x^{2}}, \text { where } x=(t-b) / c \\
& f(x)=\left(a \mathrm{e}^{-x}\right) /\left(1+\mathrm{e}^{-x}\right)^{2}, \text { where } x=(t-b) / c \\
& f(t)=a t^{2}+b t+c
\end{aligned}
$$

( $t$ varying between 1 [1 August] and 36 [5 September]). These functions were considered as possible forms of the abundance curve of the species: Function (1) is asymmetrical with post-peak abundance decreasing more slowly than it increased before peak abundance; Function (2) models a narrow window of high abundance, with few early and late-migrating individuals; and Function (3) models a parabolic curve of abundance. Separately for each year and for each species, we used, among the 3 models, the one with the lowest deviance to compute the date of maximum $N_{\mathrm{p}}$ (and associated SE). If the computation process failed for all 3 models for a given species-year dataset, indicating inappropriate fit of all the models to the data, then no estimate of peak date was available for subsequent analyses.
Theoretically, the above-described method correctly estimated peak dates, even outside of the capture session. To check for the robustness of peak date estimates, we generated 3 simulated datasets, with the migration peak dateset on 5, 17 and 28 August, and a random, normally distributed error with standard deviation taken as the maximum $N_{\mathrm{p}} / 10$. These simulated datasets were analysed through the same 3 models and with the same dates of capture as the real dataset. Each of the 3 simulations was repeated 10 times.

Estimated migration peak dates per species and per year were then used as dependent variables in a linear regression analysis to identify the best predictors of observed among-year variations in migration timing. The accurateness of peak date estimates was accounted for by including $1 / \mathrm{SE}^{2}$ as a weight of the dependent variable in the regression. Explanatory variables were: species $(S p, 2$ modalities), year $(Y$, taken as a continuous variable), monthly mean temperatures at the given site ( $T_{i}$ for temperature in the $i$ th month, $i$ varying between 02 for February to 09 for September). Preliminary to formal analysis, we tested for a linear temporal change in migration peak date throughout the study period for each species, which could be taken as indicative of a possible effect of climate change. Afterward, the analysis relied on an information theoretic approach (Burnham \& Anderson 2002), where the influence of effects on migration peak date was evaluated by multimodel inference. To restrict the number of candidate models to its minimum, models that were a priori biologically meaningless and models with interactions involving 3 terms or more were not considered. Step 1 of the selection procedure was the model with a linear effect of year only. We then compared this model with the model including temperature as an explanatory variable. Step 2 was then the exploratory analysis of the effect of temperature in different months of the year on migration peak date. Because of the lack of strong prior knowledge on which temperature should be most influential, we had to consider a relatively high number of models: 8 models of the form $S p \times T_{i}$. $T_{j}$ hereafter refers to the best temperature as selected by this procedure. We compared the model $S p \times T_{j}$ and the model with a temporal trend to evaluate if temperature was a better predictor of temporal changes than a simple directional change throughout the study period. Our model selection procedure then followed 4 more steps (1 model per step). Step 3: the interaction $S p \times T_{j}$ was removed to determine if the effect of temperature differed among species. Step 4: interaction terms among spring and autumn temperature effects were added to assess the possible interplay of spring and autumnal temperature. If a spring temperature was selected as the best 
predictor, the interaction with the temperature at the time of capture (August) was added to the model; if August temperature was selected, we added the interaction with all spring temperatures. Step 5: a linear effect of year was added to the selected temperature effect to evaluate if plastic adaptation alone (no effect of year) to temperature is the main mechanism explaining the observed change in migration peak date, or if directional natural selection was also likely to have a role (effect of year; cf. prediction from Jonzén et al. 2007 Section 1, this issue). Finally, in Step 6, we compared our final model to the model with the mean capture date as a unique explanatory variable. This allowed us to check whether biological determinants of the temporal change in migration peak date were not confounded by the possible methodological bias due to among-year changes in capture session dates. At each step, the best model was identified as the one with the lowest AIC (Akaike's information criterion), with a 2 point AIC difference when compared to other models (Burnham \& Anderson 1998). When models differed by $<2$ points of AIC, their respective probability was assessed by Akaike's weight $w_{i} w_{i}$ gives the probability that a model is the real model, given the data and given that the real model is among those included in the model selection (Burnham \& Anderson 1998, p. 124). At the end of this procedure, estimates and standard deviations of the slopes were presented. The influence of effects of interest is evaluated with Akaike's weights. Goodness of fit (GOF) was assessed by testing the normality of residuals of the best model with a Shapiro-Wilk test and through the dispersion coefficient (residual deviance/residual degree of freedom). All analyses were performed with R (R Core Development Team 2005).

\subsubsection{Stopover duration, body mass gain and correlates}

Average stopover durations per species per year per site were estimated with the software SODA 2.1.2 (Schaub et al. 2001). This CMR modelling of stopover data is advantageous because it gives access to the 'true' stopover duration, i.e. estimating the total time spent at the stopover site by summing estimates of the time spent at the site before (since arrival) and after (up to departure) the first capture, while it adjusts SOD estimates for potentially confounding variations in capture probability (hereafter noted $P$ ). Thus, it provides robust, daily, local survival (hereafter noted $\Phi$; Lebreton et al. 1992) and SOD estimates. Note that the SODA method assumes that the stopover duration is constant among birds (within seasons). Efford (2005) suggested that stopover duration may indeed vary among individuals, following a Poisson distribution. In this case, SODA estimates are shown to be twice the real SOD, and the average time of survival after first capture is a better estimate of the average SOD than SODA estimates. In the present study, we chose to rely on SODA and not on 'local survival' analysis for 3 reasons. (1) According to what is known about behavioural and meteorological determinants of migration waves in small passerines (in Pradel et al. 2005), SOD is likely to be closer to constancy among birds rather than to following a Poisson distribution (Efford 2005); thus SODA seems likely to perform better than Efford's method in a wider range of situations. (2) No statistical method allows us to identify the true distribution of SOD (Pradel et al. 2005); thus, in our case, nothing supports that the 'life expectancy' parameter (Efford 2005) would be a better approximation of SOD than SODA estimates. (3) Our parameter of interest is the SOD, i.e. the resultant of both immigration and emigration probabilities (as modelled by SODA), and not only the emigration part of the SOD strategy (Efford 2005). Note that no CMR method can account for the likely dependency of the emigration probability on the time spent at a stopover site. This is a major caveat of SOD approaches with CMR data, indicating that all studies, including ours, are to be considered exploratory (Pradel et al. 2005).

GOF was tested with the software U-Care 2.2.3 (Choquet et al. 2005) for the model [ $\Phi($ species $\times$ site $\times$ year $\times t), P($ species $\times$ site $\times$ year $\times t)$ ] to detect transients (Test 3.SR) and trap dependence (Test 3.CT). Overdispersion was tested using the overall test computed from the 4 components. Afterward, for the sake of simplicity, daily local survival was assumed to be constant within years, but varied across years, site and species, and recapture probability was assumed to vary among days and among years \{model [ $\Phi($ species $\times$ site $\times$ year $)$, $P($ species $\times$ site $\times$ year $\times t)]\}$.

DMG was calculated for individuals that were captured more than once during a single migration period. DMG is the difference in body mass divided by the number of days between 2 consecutive capture events (in $\mathrm{g} \mathrm{d}^{-1}$; averaged per individual if $>1$ recapture event was available).

Estimates of SOD per species, per site and per year were then used as dependent variables in a linear regression analysis based on model selection (same procedure and criteria as for the migration peak date analysis). The accurateness of SOD estimates was accounted for by including $1 / \mathrm{SD}^{2}$ as a weight of the dependent variable in the regression. In a first step, we computed separate univariate linear regressions for each species to obtain comparable estimates of the slope of the effect of DMG on SOD (potentially useful for future analysis). We also tested the relationship 
between DMG and $T_{i}$ with separate linear models. We then compared a set of models including the effect of DMG in addition to the effects of temperature, site and species. Step 1: we departed from the model $S+S p \times$ $\mathrm{DMG}$, i.e. the model with no temperature or year effect. The exploratory analysis of the effect of temperature was conducted in Step 2, where we compared 8 models of the form $S+S p \times T_{i}+S p \times$ DMG ( $S$ for site, other effects noted as in the previous section), where only the effect monthly temperature was allowed to change. $T_{\mathrm{k}}$ refers to the temperature selected during this first phase. The model $S+S p \times T_{\mathrm{k}}+S p \times \mathrm{DMG}$ was compared to the model of Step 1 to evaluate the importance of temperature as a determinant of SOD. Then, inference was based on 7 more steps of model selection (1 model per step). Step 3: a model without the DMG effect was compared to the model selected in Step 2 to confirm that DMG was an important predictor of the SOD. Step 4: a model with a linear effect of year alone was compared to the model selected in Step 2 to confirm that the predicted plastic adaptation of SOD to DMG and $T_{\mathrm{k}}$ was a better determinant of the estimated SOD than a directional change throughout the study period. Step 5: the interaction $S p \times T_{\mathrm{k}}$ was removed from model $S+S p \times T_{\mathrm{k}}+S p \times$ DMG to determine if species responded differently to temperature. Step 6: the interaction $S p \times D M G$ was removed to evaluate if species adjusted their SOD to DMG differently. Step 7: a linear effect of year was added to a model $S+S p \times T_{\mathrm{k}}+S p \times \mathrm{DMG}$, where the interactions not selected in Steps 3 and 4 had been removed. If plastic adaptation to the experienced conditions, as approximated by DMG and $T_{\mathrm{k}}$, is the only component of the observed variations, the temporal trend should not be selected. Step 8: the interaction $S \times \mathrm{DMG}$ was added to check whether the effect of DMG differed among sites. Finally, Step 9: the interaction $T_{\mathrm{k}} \times \mathrm{DMG}$ was added to determine if DMG mediated the effect of temperature on SOD. At the end of this procedure, estimates and SD were presented. GOF was assessed by testing the normality of residuals of the best model with a Shapiro-Wilks test and through the dispersion coefficient (residual deviance/residual degree of freedom).

\section{RESULTS}

\subsection{Evolution of mean monthly temperatures}

Mean temperatures in February, March, April and September were positively correlated to year $\left(\right.$ all $\mathrm{r}^{2}>0.3$ and $\mathrm{p}<0.01)$. Slopes were, respectively, $0.25 \pm 0.072$, $0.16 \pm 0.047,0.09 \pm 0.031$ and $0.11 \pm 0.033^{\circ} \mathrm{C} \mathrm{yr}^{-1}$. Mean temperature in August was not related to year ( $p>0.5)$.

\subsection{Phenology, peak date and temperature}

The peak dates computed from the simulated datasets with fixed migration timing exhibited no advance with year (all $3 \mathrm{p}>0.5$ ) and were correctly estimated (average estimated peak date for the 3 simulated datasets: $5 \pm 1.0,18 \pm 1.5,28 \pm 1.2$, for simulated peak date of 5, 17 and 28 August, respectively). Thus, the method to compute migration peak dates produced estimates robust to among-year variations in dates of capture sessions in our simulated cases.

In the real dataset, peak dates were obtained for all but 3 species-years (Fig. 1). The second functional form was selected as the best descriptor of the $N_{p}$ phenological pattern in 29 species-year datasets out of 46.

Peak date was negatively correlated to the year for SW (linear model: $\mathrm{r}^{2}=0.51$, slope $=-0.72 \pm 0.16 \mathrm{~d} \mathrm{yr}^{-1}$; Fig. 1) and RW (linear model: $r^{2}=0.87$, slope $=-0.78 \pm$ $0.067 \mathrm{~d} \mathrm{yr}^{-1}$ : Fig. 1). Pooled together, both species shifted peak date by $-0.73 \pm 0.086 \mathrm{~d} \mathrm{yr}^{-1}$. As average temperatures have increased, there was a potential effect of climate change on migration timing to investigate. Temperatures were far better in determining the timing of migration than a linear temporal trend (Table 1, Step 2.2 vs. Step 1). The selection procedure gave temperature in March as the most important factor (Table 1, Steps 2.1 to 2.8: AIC differences between Step 2.2 and the others are $>30$ points). The interspecific difference in migration timing could be neglected (Table 1, Step 3 vs. 2.2: weight ratio indicates that the model with no interspecific difference is 6.3 more likely than the model with species differences). Both species migrated earlier in years of warmer March temperatures (estimate of the slope in Step 3: $-2.54 \pm$ $0.19 \mathrm{~d}^{\circ} \mathrm{C}^{-1}$ ). The estimated migration timing, which

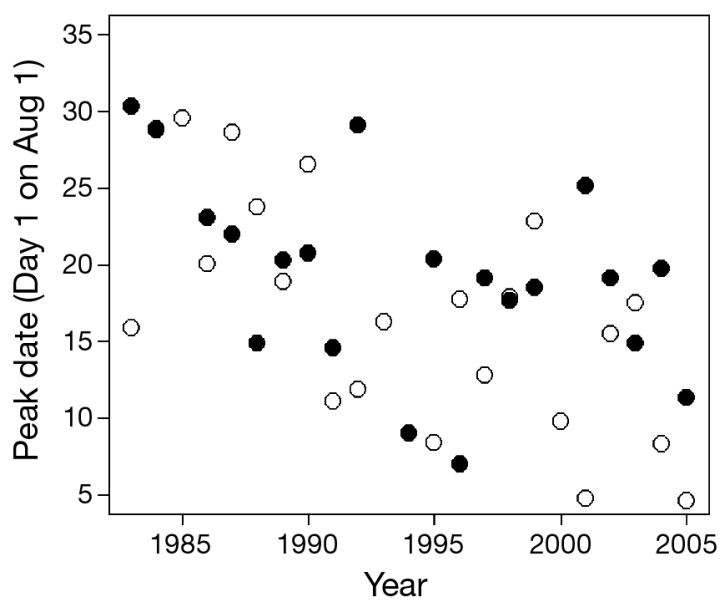

Fig. 1. Acrocephalus schoenobaenus and A. scirpaceus. Peak date of the post-breeding migration of sedge warblers $(\mathrm{SW}, \mathbf{0})$ and reed warblers $(\mathrm{RW}, \mathrm{O})$ 
Table 1. Model selection for peak date, second phase. Sp: effect of species; $Y$ : linear effect of year; $T_{i}$ : linear effect of mean temperature in the $i$ th month; $C$ : linear effect of mean date of capture sessions; w: Akaike's weight. Best models are indicated in bold. Shapiro-Wilks normality test on residuals of model $\sim T_{03}: W=0.9774, \mathrm{p}=0.5465$; dispersion coefficient: 21.2. AIC: Akaike's information criterion

\begin{tabular}{|c|c|c|c|}
\hline Step & Model & AIC & $w$ \\
\hline \multicolumn{4}{|c|}{ Linear temporal change } \\
\hline 1 & $\sim Y$ & 334.1 & $1.87 \times 10^{-7}$ \\
\hline \multicolumn{4}{|c|}{ Influence of monthly temperatures per species } \\
\hline 2.1 & $\sim S p \times T_{02}$ & 361.18 & $2.47 \times 10^{-13}$ \\
\hline 2.2 & $\sim S p \times T_{03}$ & 308.85 & 0.06 \\
\hline 2.3 & $\sim S p \times T_{04}$ & 359.65 & $5.31 \times 10^{-13}$ \\
\hline 2.4 & $\sim S p \times T_{05}$ & 376.33 & $1.27 \times 10^{-16}$ \\
\hline 2.5 & $\sim S p \times T_{06}$ & 368.66 & $5.87 \times 10^{-15}$ \\
\hline 2.6 & $\sim S p \times T_{07}$ & 372.95 & $6.87 \times 10^{-16}$ \\
\hline 2.7 & $\sim S p \times T_{08}$ & 368.82 & $5.42 \times 10^{-15}$ \\
\hline 2.8 & $\sim S p \times T_{09}$ & 339.82 & $1.07 \times 10^{-8}$ \\
\hline \multicolumn{4}{|c|}{$\begin{array}{l}\text { Most influential monthly temperature without species } \\
\text { differences }\end{array}$} \\
\hline 3 & $\sim T_{03}$ & 305.04 & 0.38 \\
\hline \multicolumn{4}{|c|}{$\begin{array}{l}\text { Interaction between most influential monthly temperature } \\
\text { and August temperature }\end{array}$} \\
\hline 4 & $\sim T_{03} \times T_{08}$ & 305.36 & 0.33 \\
\hline \multicolumn{4}{|c|}{ Temporal linear trend in addition to March temperature } \\
\hline & $\sim T_{03}+Y$ & 306.03 & 0.23 \\
\hline \multicolumn{4}{|c|}{ Effect of capture dates } \\
\hline 6 & $\sim C$ & 326.79 & $7.25 \times 10^{-6}$ \\
\hline
\end{tabular}

mainly takes place in August, may thus be influenced by the interaction of March and August temperatures. However, comparing Step 3 vs. Step 4 provides weak support for such an interaction effect of August temperatures: the model with interaction is about as likely as the model without interaction. The model including the interactions suggests that warm August temperature tended to moderate the effect of warm March temperatures (Table 2: interaction term in the model $\sim T_{03} \times$ $T_{08}$ ), with no apparent additive effect of August temperatures. The additive temporal trend did not markedly improve the fit (Step 5 vs. Step 3): the model without temporal trend was slightly (1.6 times) more likely than the model with the trend. It suggests that most among-year variation was explained by temperature.

Table 2. Parameter estimates from the model $T_{03} \times T_{08}$ for peak date. $T_{i}$ : linear effect of mean temperature in the ith month

\begin{tabular}{|lrr|}
\hline Parameter & Estimate & \multicolumn{1}{c|}{ SE } \\
\hline Intercept & 61.3327 & 27.4964 \\
$T_{03}$ & -6.7763 & 3.2502 \\
$T_{08}$ & -1.1313 & 1.5488 \\
$T_{03} \times T_{08}$ & 0.2219 & 0.1791 \\
\hline
\end{tabular}

The effect of capture dates was not selected (weight of Step $6<0.01$ in Table 1), further emphasising that the true temporal variations in migration peak date were not strongly biased by changing capture dates among years. Finally, a linear temporal trend alone was a worse predictor of among-year variations in migration peak date when compared to the predictive power of temperature models, with a probability $<0.01$ (weight of Step 1 in Table 1). All models including a year effect (Steps 1 and 5) had a summed weight of 0.23 .

\subsection{Stopover duration, body mass gain and temperature}

Some lack of fit of the general model used for SOD estimation $[\Phi($ species $\times$ site $\times$ year $\times t), P($ species $\times$ site $\times$ year $\times t$ )] due to the excess of individuals captured only once (transience, Test 3.SR) was detected in 18 species by site by year subsets out of 62 ( $p<0.05$ in Table 3). If we corrected these GOF tests for multiple testing, the detected lack of fit would be even more restricted. Moreover, transience in itself is a biologically meaningful phenomenon in the context of migration stopover, since individuals migrating through the area without remaining for a stopover are de facto transients. Thus, models were not adjusted to discard transients from SOD estimates (Schaub et al. 2001). No other source of lack of fit of the general model to the data was detected (trap-dependence, Test 3.CT: all p > 0.05; overall fit, global tests: all $\mathrm{p}>$ 0.05 , indicating absence of overdispersion).

Table 3. Acrocephalus schoenobaenus and A. scirpaceus. Goodness of fit: p-values of Test 3.SR corresponding to each species-site-year subset of data for sedge warblers (SW) and reed warblers (RW). A value $<0.05$ (bold font) indicates a significant transience effect. -: data were too sparse to compute the test

\begin{tabular}{|c|c|c|c|c|c|c|}
\hline \multirow[b]{2}{*}{ Year } & \multicolumn{3}{|c|}{$\longrightarrow \mathrm{SW} \longrightarrow$} & \multicolumn{3}{|c|}{ - RW- } \\
\hline & S29 & S44 & S76 & S29 & S44 & S76 \\
\hline 1994 & 0.86 & 0.20 & - & 0.84 & 0.87 & - \\
\hline 1995 & 0.00 & 1.00 & - & 0.83 & 0.24 & 1.00 \\
\hline 1996 & 0.01 & 0.29 & - & 0.31 & 0.42 & - \\
\hline 1997 & 0.39 & 0.98 & - & 0.82 & 0.09 & - \\
\hline 1998 & 0.01 & 0.80 & - & 0.54 & 0.23 & - \\
\hline 1999 & 0.02 & 0.48 & 1.00 & 0.44 & 0.00 & - \\
\hline 2000 & 0.96 & 0.88 & 0.50 & 0.27 & 0.01 & 0.08 \\
\hline 2001 & 0.96 & 0.00 & 0.18 & 0.79 & 0.00 & 0.33 \\
\hline 2002 & 0.61 & 0.00 & 1.00 & 0.40 & 0.00 & 0.15 \\
\hline 2003 & 0.12 & 0.04 & 0.00 & 0.08 & 0.00 & 0.01 \\
\hline 2004 & 0.03 & 0.05 & 1.00 & 0.09 & 0.75 & 0.51 \\
\hline 2005 & 0.04 & 0.77 & 0.91 & 0.01 & 0.04 & 0.11 \\
\hline
\end{tabular}



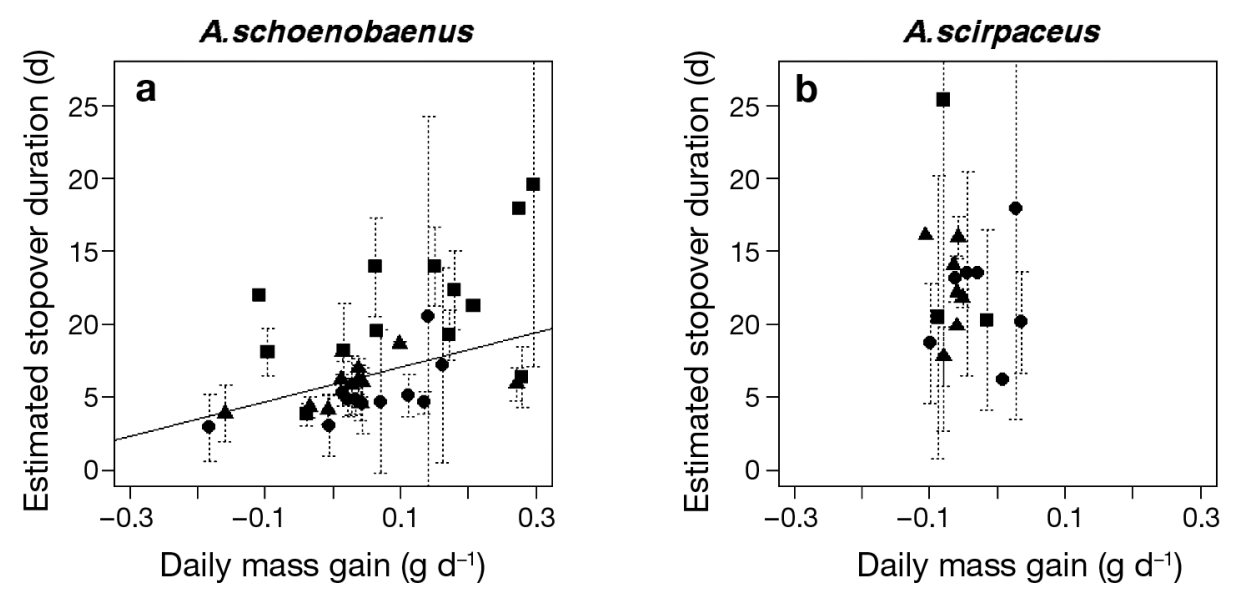

Fig. 2. Acrocephalus schoenobaenus and A. scirpaceus. Variation of stopover duration estimates with daily mass gain estimates for (a) sedge warblers (SW) and (b) reed warblers (RW). Error bars: SD of the stopover duration estimates. Unbroken line in

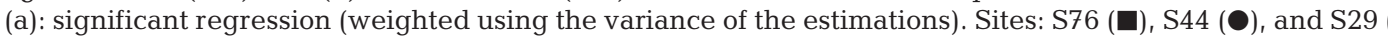

Separate linear models built for each species suggested that DMG had a positive effect on SOD in SW $\left(\mathrm{r}^{2}=0.31\right.$, slope $=9.37 \pm 3.79 \mathrm{~d}^{2} \mathrm{~g}^{-1} ;$ Fig. 2$)$, but not in RW ( ${ }^{2}=0.018$; Fig. 2). The effect of DMG was selected by the AIC-based selection procedure (Table 4, Step 3 vs. Step 2.7: >40 AIC points).

The temporal linear trend alone was strongly unlikely (>90 AIC points more than the best model). The AIC-based procedure retained August temperature as the best predictor of SOD estimates (Table 4, Steps 2.1 to 2.8: AIC differences between Step 2.7 and the others is always $>18$ ), and this effect of temperature was very likely (Step 2.7 vs. Step 1: weight ratio indicates that the model with the temperature effect is $>10^{6}$ times more likely than the model without). The interspecific difference in the response to temperature was retained (Table 4, Step 2.7 vs. Step 5: the model with interaction is 4.8 times more likely), but adjustment of SOD according to experienced DMG did not seem to vary among the 2 species (Table 4, Step 6 vs. Step 2.7: the model without interspecific difference is 2.2 times more likely). Adding a linear temporal trend markedly improved the fit (Step 7 vs. Step 6). The interaction between DMG and August temperatures affected SOD estimates (Step 9 vs. Step 7: model with interaction is 2.8 times more likely), and this was a stronger effect than the potential differential effect of DMG among sites (Step 9 vs. Step 8: model including DMG interaction with site was 9 times less likely than model including interaction with temperature, suggesting that among-site differences in SOD response to DMG were low.

Estimates (Table 5) indicated that the warmer the autumn and the higher the experienced DMG, the longer the stopover (Table 5: effects $T_{08}$ and DMG). RW
Table 4. Model selection for stopover duration. Sp: effect of species; $S$ : effect of site; $Y$ : linear effect of year; DMG: linear effect of daily mass gain; $T_{i}$ : linear effect of mean temperature in the ith month; $w$ : Akaike's weight. Models are presented in the order followed in the procedure. Best models are indicated in bold. Shapiro-Wilks normality test on residuals of model $\sim S+S p \times T_{08}+T_{08} \times \mathrm{DMG}+Y: W=0.815, \mathrm{p}<$ 0.01; dispersion coefficient: 1.05. AIC: Akaike's information criterion

\begin{tabular}{|c|c|c|c|}
\hline Step & Model & $\mathrm{AIC}$ & $w$ \\
\hline \multicolumn{4}{|c|}{ Model without temperature effect } \\
\hline 1 & $\sim S+S p \times \mathrm{DMG}$ & 202.5 & $6.85 \times 10^{-10}$ \\
\hline \multicolumn{4}{|c|}{ Influence of monthly temperatures per species } \\
\hline 2.1 & $\sim S+S p \times T_{02}+S p \times \mathrm{DMG}$ & 195.32 & $2.48 \times 10^{-8}$ \\
\hline 2.2 & $\sim S+S p \times T_{03}+S p \times \mathrm{DMG}$ & 191.03 & $2.12 \times 10^{-7}$ \\
\hline 2.3 & $\sim S+S p \times T_{04}+S p \times \mathrm{DMG}$ & 198.181 & $5.93 \times 10^{-9}$ \\
\hline 2.4 & $\sim S+S p \times T_{05}+S p \times \mathrm{DMG}$ & 196.85 & $1.15 \times 10^{-8}$ \\
\hline 2.5 & $\sim S+S p \times T_{06}+S p \times \mathrm{DMG}$ & 198.10 & $6.18 \times 10^{-9}$ \\
\hline 2.6 & $\sim S+S p \times T_{07}+S p \times \mathrm{DMG}$ & 202.27 & $7.68 \times 10^{-10}$ \\
\hline 2.7 & $\sim S+S p \times T_{08}+S p \times \mathrm{DMG}$ & 172.08 & $2.76 \times 10^{-3}$ \\
\hline 2.8 & $\sim S+S p \times T_{09}+S p \times \mathrm{DMG}$ & 197.68 & $7.62 \times 10^{-9}$ \\
\hline \multicolumn{4}{|c|}{ Model without DMG effect } \\
\hline 3 & $\sim S+S p \times T_{08}$ & 212.44 & $4.75 \times 10^{-12}$ \\
\hline \multicolumn{4}{|c|}{ Linear temporal change } \\
\hline 4 & $\sim Y$ & 255.61 & $2.01 \times 10^{-21}$ \\
\hline \multicolumn{4}{|c|}{$\begin{array}{l}\text { Most influential monthly temperature without species } \\
\text { differences }\end{array}$} \\
\hline 5 & $\sim S+T_{08}+S p \times \mathrm{DMG}$ & 175.20 & $5.80 \times 10^{-4}$ \\
\hline \multicolumn{4}{|c|}{ No interspecific difference in response to DMG } \\
\hline 6 & $\sim S+S p \times T_{08}+\mathrm{DMG}$ & 170.49 & 0.01 \\
\hline \multicolumn{4}{|c|}{ Temporal linear trend in addition to former model } \\
\hline 7 & $\sim S+S p \times T_{08}+\mathrm{DMG}+Y$ & 163.12 & 0.24 \\
\hline \multicolumn{4}{|c|}{ Among-site differences in the effect of DMG } \\
\hline & $\sim S+S p \times T_{08}+S \times \mathrm{DMG}+Y$ & 165.49 & 0.07 \\
\hline \multicolumn{4}{|c|}{ Effect of DMG depending on temperature } \\
\hline & $S+S p \times T_{08}+T_{08} \times \mathrm{DMG}+Y$ & 161.09 & 0.67 \\
\hline
\end{tabular}


Table 5. Parameter estimates from the model SOD $\sim S+S p \times$ $T_{08}+T_{08} \times \mathrm{DMG}+Y$. Intercept is sedge warbler Acrocephalus schoenobaenus (SW) and Site S29. SpRW: effect of the species reed warbler A. scirpaceus; S44 and S76: effect of those sites; $Y$ : linear effect of year; DMG: linear effect of daily mass gain; $T_{08}$ : linear effect of mean temperature in August

\begin{tabular}{|lrr|}
\hline Parameter & Estimates & \multicolumn{1}{c|}{ SE } \\
\hline Intercept & 405.74742 & 122.96557 \\
S44 & -2.08310 & 0.53738 \\
S76 & -1.02143 & 0.67529 \\
SpRW & -31.81739 & 23.72507 \\
$T_{08}$ & 0.99588 & 0.18343 \\
DMG & 61.24120 & 30.10817 \\
$Y$ & -0.20867 & 0.06171 \\
SpRW $\times T_{08}$ & 1.96604 & 1.26845 \\
$T_{08} \times$ DMG & -3.16255 & 1.71606 \\
\hline
\end{tabular}

tended to stay longer than SW in warm autumns (interaction $\mathrm{SpRW} \times T_{08}$ in Table 5). Values of the estimates suggested that temperature was more important when DMG was negative, and reciprocally the effect of DMG was stronger at low temperatures (interaction $T_{08} \times$ DMG in Table 5). When tested with separate linear models, the temperatures (August) had no effect on DMG (regression DMG $T_{i}, \mathrm{p}>0.5$ in both species and at all 3 sites), showing that DMG did not mediate the response to temperature. In addition, there was a significant linear trend for SOD to decrease through years, both species staying for shorter time periods in recent years (effect $Y$ in Table 5).

\section{DISCUSSION}

\subsection{Inter-annual variations in the timing of migra- tion and correlation with spring temperature}

In both species sedge warblers Acrocephalus schoenobaenus and reed warblers $A$. scirpaceus the migration peaks occurred earlier in recent years. The best predictor of peak date was spring (March) temperature, post-nuptial migration culminating earlier in years with warm springs. This fits the prediction that spring temperatures are a better determinant of autumnal migration timing than summer or autumnal temperatures. Evidence for this phenomenon remains quite rare (Sokolov et al. 1999, Sokolov 2006).

Since both species advanced their migration date in years with warm springs, neither species takes advantage of climate warming to spend more time in their temperate breeding grounds. This supports the hypothesis that the advance in departure dates is explained by fitness benefits from early arrival at wintering grounds, rather than by temporal constraints on food availability en route. However, we acknowledge that the latter conclusion is based on the assumption of a possible differential change in phenology of the food availability between the 2 species (Bibby \& Green 1981).

The data and methods we used suffered from 3 main caveats or limits. First, at Site S76, the averaged duration of capture sessions per year was ( $50 \%)$ smaller than the total duration of fall migration, and the dates of capture sessions advanced throughout the years. However, we are confident that the observed advance in peak date is the expression of a biological phenomenon and not the result of a bias due to data or methodology caveats. Simulations proved that migration peaks occurring outside the migration period actually monitored were satisfactorily retrieved by the models used for estimating peak date. The linear effects of year and temperatures were far better determinants of among-year variations in peak date than mean capture-session dates, which suggests that the capture sessions overlapped enough with the main peak to allow the models to fit the main modality in most years. Second, migration timing was (reasonably) assumed to be unimodal (the method used could estimate 1 peak date per year only), and among-age differences in migration timing (e.g. Caillat et al. 2005) were ignored. Future studies may therefore explore the use of multimodal modelling methods of migration timing. And among-year variations in migration peak date may be analysed separately per age class. It would be particularly interesting to know what degree of among-year variations in migration timing could be accounted for by the interaction between age-differential timing (cf. bimodality) of migration and amongyear variations in reproductive success (cf. age ratio). Finally, the number of fitted models (14) to explain among-year variations in migration peak date was high compared to the number of statistical units (43 species-years). As stressed by Burnham \& Anderson (2002), this increases the risk of selecting a 'best' model that indeed has a weak explanatory power. Future tests of our predictions with datasets from other sites and species will indicate how robust and general our conclusions are.

\subsection{Stopover duration and correlates}

Among-site, -year and -species variations in SOD estimates were best explained by DMG, August temperatures and linear year effect. DMG did not depend on temperature. This suggests that the advance in migration timing is sufficient for the birds not to experience any decrease in food availability at stopover sites (which would have resulted in a decrease in DMG and SOD with increasing spring temperature; Hedenström et al. 2007). Even if an advance in the timing of 
food abundance en route is not the driving force of the advanced timing of migration, this advance seems sufficient to track the possible changes in the phenology of autumn food resources and to avoid any decrease in the experienced food abundance. If the advance in peak date with increasing $T_{03}$ had not been sufficient, birds (and especially SW) would potentially have experienced a decrease in autumn food resources and we should have observed a decrease of DMG and SOD with $T_{03}$. This decrease is not observed, suggesting that birds efficiently adapted to the newly experienced conditions. This interpretation lays on the assumption that there is a modification of food resource phenology. Even if this assumption is not verified, our results still support that recent climate warming did not affect the stopover duration.

The fact that the relationship between SOD and DMG is positive is in agreement with theoretical work on time-minimising migrants using a discrete environment (Alerstam \& Lindström 1990, Hedenström et al. 2007). The significance threshold reached in SW only brings to the fore the influence of diet involved in our second hypothesis: SW was predicted to be more constrained than RW and, as a result, to respond more strongly to variations in its experienced DMG, because when the resource peaks somewhere, it is already scarce further south. This result is in agreement with previous findings by Schaub \& Jenni (2001) that between-site variation of SOD is much greater for SW than for species with a more reliable food resource. However, when analysing both species with a single model, the interspecific difference was not significant. The much higher variability of DMG in SW than in RW may mask this difference.

\subsection{Observed temporal trend: Phenotypic plasticity or natural selection?}

For both species, migration timing is better predicted by a physical variable (March temperature) than by a linear year effect alone. Among-year adjustment of migration timing to temperature conditions suggests that the observed changes in migration behaviour would be essentially plastic (Jonzén et al. 2006). Since no temporal linear change in migration date is found after correction for temperature, then directional selection for earlier migration either does not operate, or is too weak to be detected. The influence of August temperatures on migration timing (through its interaction with March temperature) and on SOD further support that SOD and migration date are adjusted to experienced conditions thanks to phenotypic plasticity rather than by natural selection-August temperatures not being correlated to year.
However, both species show a significant decrease in stopover duration with year that is explained neither by DMG nor by temperatures. This result is more difficult to interpret. The linear year effect might integrate some other factors that we did not include in this analysis. Since DMG did not depend on year or on temperature, we do not think that site quality decreases with year.

Particularly for SW, the DMG might be the integrative clue used by individuals to plastically adapt their stopover duration to local conditions. DMG is much more variable in this species, and this may be due to its specialised diet (Bibby \& Green 1981, Schaub \& Jenni 2001). As our results suggest that the advance in migration timing does not occur in response to the temporal shift in food availability, mistiming between migration and appearance of the aphid peak is possible in the coming years. The future evolution of the system will allow further testing of this hypothesis. We will need to quantify the temporal variations in aphid abundance and their relationships with spring and autumn temperatures, as well as with the diet and stopover duration of both warblers in relationship to aphid availability.

Acknowledgements. We warmly thank all ringers who collected data, and F. Jiguet and J.-M. Moisselin (Meteo France) for providing temperature data. Ringing licenses were delivered by CRBPO, Muséum National d'Histoire Naturelle. We are grateful to 4 anonymous reviewers for their constructive comments, and to R. Choquet and O. Gimenez for their help in data analysis.

\section{LITERATURE CITED}

Alerstam T, Lindström A (1990) Optimal bird migration: the relative importance of time, energy and safety. In: Gwinner E (ed) Bird migration: physiology and ecophysiology. Springer-Verlag, Berlin, p 331-351

Austin GE, Rehfisch MM (2005) Shifting nonbreeding distributions of migratory fauna in relation to climatic change. Glob Change Biol 11:31-38

Bargain B, Vansteenwegen C, Henry J (2002) Importance des marais de la Baie d'Audierne (Bretagne) pour la migration du Phragmite des joncs Acrocephalus schoenobaenus. Alauda 70:37-55

Bergmann F (1999) Long-term increase in numbers of earlyfledged reed warblers (Acrocephalus scirpaceus) at Lake Constance (southern Germany). J Ornithol 140:81-86

Bibby CJ, Green RE (1981) Autumn migration strategies of reed and sedge warblers. Ornis Scand 12:1-12

Both C, Visser ME (2001) Adjustment to climate change is constrained by arrival date in a long-distance migrant bird. Nature 411:296-298

Both C, Bijlsma RG, Visser ME (2005) Climatic effects on timing of spring migration and breeding in a long-distance migrant, the pied flycatcher Ficedula hypoleuca. J Avian Biol 36:368-373

Burnham KP, Anderson DR (1998) Model selection and inference: a practical information-theoretic approach. SpringerVerlag, New York 
Burnham KP, Anderson DR (2002) Model selection and multimodel inference: a practical information-theoretic approach, 2nd edn. Springer-Verlag, New York

Caillat M, Dugué H, Leray G, Gentric A, Pourreau J, Julliard $\mathrm{R}$, Yésou P (2005) Résultat de 10 années de baguage de fauvettes paludicoles Acrocephalus sp. dans l'estuaire de la Loire. Alauda 73:375-388

Choquet R, Reboulet AM, Lebreton JD, Gimenez O, Pradel R (2005) U-CARE 22 user's manual. CEFE, Montpellier

Cleland EE, Chiariello NR, Loarie SR, Mooney HA, Field CB (2006) Diverse responses of phenology to global changes in a grassland ecosystem. Proc Natl Acad Sci USA 103: 13740-13744

Cotton PA (2003) Avian migration phenology and global climate change. Proc Natl Acad Sci USA 100:12219-12222

Cramp S (1992) The birds of the western Palearctic, Vol 6. Oxford University Press

Crick HQP, Sparks TH (1999) Climate change related to egglaying trends. Nature 399:423-424

Crick HQP, Dudley C, Glue DE, Thomson DL (1997) UK birds are laying eggs earlier. Nature 388:526

Efford MG (2005) Migrating birds stop over longer than usually thought. Comment. Ecology 86:3415-3418

Gatter W (1992) Timing and patterns of visible autumn migration-Can effects of global warming be detected? J Ornithol 133:427-436

Gordo O (2007) Why are bird migration dates shifting? A review of weather and climate effects on avian migratory phenology. Clim Res 35:37-58

Gordo O, Sanz JJ (2006) Climate change and bird phenology: a long-term study in the Iberian Peninsula. Glob Change Biol 12:1993-2004

Grosbois V, Henry PY, Blondel J, Perret P, Lebreton JD, Thomas DW, Lambrechts MM (2006) Climate impacts on Mediterranean blue tit survival: an investigation across seasons and spatial scales. Glob Change Biol 12:2235-2249

Hedenström A, Barta Z, Helm B, Houston AI, McNamara JM, Jonzén N (2007) Migration speed and scheduling of annual events by migrating birds in relation to climate change. Clim Res 35:79-91

Idrissi HR, Lefebvre G, Poulin B (2004) Diet of reed warblers Acrocephalus scirpaceus at two stopover sites in Morocco during autumn migration. Rev Ecol (Terre Vie) 59:491-502

Jenni L, Kéry M (2003) Timing of autumn bird migration under climate change: advances in long-distance migrants, delays in short-distance migrants. Proc R Soc Lond B Biol Sci 270:1467-1471

Jonzén N, Linden A, Ergon T, Knudsen E and others (2006) Rapid advance of spring arrival dates in long-distance migratory birds. Science 312:1959-1961

Jonzén N, Ergon T, Lindén A, Stenseth NC (2007) Bird migration and climate: the general picture and beyond. Clim Res 35:177-180

Lebreton JD, Burnham KP, Clobert J, Anderson DR (1992) Modeling survival and testing biological hypotheses using marked animals - a unified approach with case-studies. Ecol Monogr 62:67-118

Lehikoinen E, Sparks TH, Zalakevicius M (2004) Arrival and departure dates. In: Møller AP, Fiedler W, Berthold P (eds) Birds and climate change. Adv Ecol Res 35:1-31

Submitted: April 28, 2007; Accepted: October 30, 2007
Marra PP, Hobson KA, Holmes RT (1998) Linking winter and summer events in a migratory bird by using stable-carbon isotopes. Science 282:1884-1886

Møller AP (2001) Heritability of arrival date in a migratory bird. Proc R Soc Lond B Biol Sci 268:203-206

Myneni RB, Keeling CD, Tucker CJ, Asrar G, Nemani RR (1997) Increased plant growth in the northern high latitudes from 1981 to 1991. Nature 386:698-702

Pradel R, Schaub M, Jenni L, Lebreton JD (2005) Migrating birds stop over longer than usually thought. Reply. Ecology 86:3418-3419

R Core Development Team (2005) R: a language and environment for statistical computing. R Foundation for Statistical Computing, Vienna. Available at http://www.R-project.org

Rivalan P, Frederiksen M, Loïs G, Julliard R (2007) Contrasting responses of migration strategies in two European thrushes to climate change. Glob Change Biol 13:275-287

Root TL, Price JT, Hall KR, Schneider SH, Rosenzweig C, Pounds JA (2003) Fingerprints of global warming on wild animals and plants. Nature 421:57-60

Roy DB, Sparks TH (2000) Phenology of British butterflies and climate change. Glob Change Biol 6:407-416

Rubolini D, Møller AP, Rainio K, Lehikoinen E (2007) Intraspecific consistency and geographic variability in temporal trends of spring migration phenology among European bird species. Clim Res 35:135-146

Salewski V, Bairlein F, Leisler B (2002) Different wintering strategies of two Palearctic migrants in West Africa-A consequence of foraging strategies? Ibis 144:85-93

Schaefer T, Ledebur G, Beier J, Leisler B (2005) Reproductive responses of two related coexisting songbird species to environmental changes: global warming, competition, and population sizes. J Ornithol 147:47-56

Schaub M, Jenni L (2001) Variation of fuelling rates among sites, days and individuals in migrating passerine birds. Funct Ecol 15:584-594

Schaub M, Pradel R, Jenni L, Lebreton JD (2001) Migrating birds stop over longer than usually thought: an improved capture-recapture analysis. Ecology 82:852-859

Sokolov L (2006) Effect of global warming on the timing of migration and breeding of passerine birds in the 20th century. Entomol Rev 86:S59-S81

Sokolov LV, Markovets MY, Morozov YG (1999) Long-term trends in the timing of spring migration of passerines on the Courish Spit of the Baltic Sea. Avian Ecol Behav 2: $1-18$

Sparks TH, Braslavska O (2001) The effects of temperature, altitude and latitude on the arrival and departure dates of the swallow Hirundo rustica in the Slovak Republic. Int J Biometeorol 45:212-216

Studds CE, Marra PP (2007) Linking fluctuations in rainfall to nonbreeding season performance in a long-distance migratory bird, Setophaga ruticilla. Clim Res 34:115-122

Trenberth KE, Jones PD, Ambenje P, Bojariu R and others (2007) Observations: surface and atmospheric climate change. In: Solomon S, Qin DM, Chen Z, Marquis M, Averyt KB, Miller HL (eds) Climate change 2007: the physical science basis. Contribution of Working Group I to the 4th Assessment Report of the Intergovernmental Panel on Climate Change. Cambridge University Press, Cambridge

Proofs received from author(s): December 14, 2007 